doi: $10.1111 /$ joes. 12030

\title{
EXPERIMENTAL LABOR MARKETS AND POLICY CONSIDERATIONS: INCOMPLETE CONTRACTS AND MACROECONOMIC ASPECTS
}

\author{
Fortuna Casoria and Arno Riedl \\ Maastricht University
}

\begin{abstract}
This survey focuses on experimental labor markets investigating two aspects that are important for a better understanding of labor market relations and their consequences for labor market policies. The first part of the survey is dedicated to papers that assess the prevalence of reciprocal considerations in incomplete labor contracts. The second part summarizes the relatively small but growing experimental literature exploring labor market issues in macroeconomics and public finance studying the interaction between taxation and labor market outcomes.
\end{abstract}

Keywords. Gift-exchange; Incomplete contracts; Labor markets; Labor market policy; Laboratory experiment

\section{Introduction}

Experimental economics' focus on the functioning of labor markets has been growing over the years and the advantages of applying experimental economics methods to labor economics have been extensively discussed (see, e.g., Fehr et al., 2009; Charness and Kuhn, 2011). Experiments allow for tight control over the many environmental factors that can affect behavior and render causal relations easier to infer. The possibility of controlling these factors implies the possibility of varying them and studying whether and to what degree the enforced changes affect decisions. This feature seems to be particularly suitable to analyze labor markets, where a large amount of labor-related available data are circumstantial, implying that it becomes difficult to exactly discern which factors play which role in the realization of outcomes.

The experimental labor economics literature is quite extensive with a wide range of issues addressed and this survey does neither intend nor pretend to cover the experimental labor literature in all its breath. We rather focus on two aspects that are important for a better understanding of labor market relations and their consequences for labor market policies. The first part of the survey is dedicated to papers that assess the prevalence of reciprocal considerations in incomplete labor contracts. The second part summarizes the relatively small but growing experimental literature exploring labor issues in macroeconomics and public finance studying the interaction between taxation and labor market outcomes. Readers interested in other aspects explored in experimental labor economics, such as work incentives or multitask problems, arbitration, job search, or gender differentials, are referred to the excellent reviews of Charness and Kuhn (2011) and Fehr et al. (2009).

Labor relations are often contractually incomplete in the sense that effort is typically not (fully) contractible or enforceable by a third party. This feature leaves room for reciprocal motivations to play a role in the work process as workers' general job attitudes become important (Fehr and Falk, 1999). The gift-exchange game, first implemented and introduced into the literature by Fehr et al. (1993), was 
designed to mimic precisely this situation. It tests the gift-exchange hypothesis of efficiency wage theory (Akerlof, 1982; Akerlof and Yellen, 1988, 1990), according to which there is a positive (i.e., reciprocal) relationship between the wages offered by firms and the effort exerted by workers. In a gift-exchange market wage offers are binding, while workers can discretionarily choose the amount of effort they exert. Experimental evidence has shown that a positive relation between wages and effort indeed emerges in such markets. Next to providing a survey of the main results related to the existence of this positive wage-effort relation, we also report on those studies that have tried to assess the implication of these findings for policy making. In addition, the robustness of the positive wage-effort relation is surveyed showing that while it survives many institutional variations and experimental conditions, there are also some environmental factors under which gift-exchange has difficulties to emerge.

The possibility of using laboratory experiments to better understand the functioning of markets has been mostly utilized for studying causal relationships at the micro level. However, lab experiments can also be a valuable research tool for gaining insights into the effects of alternative labor policies or institutions at a macro level. Indeed, the main strengths of the experimental method, control and replication, can be very useful in the domain of macroeconomics, which traditionally relies on circumstantial field data which may suffer from data non-availability, endogeneity, or measurement error. This implies that the causal impact of a given variable, for example, an increase of a labor tax, on economic performance may be difficult to assess. Experimental labor economics can be useful in such a macroeconomics context and help to overcome some of these problems. The second part of this survey focuses on the small but growing literature of laboratory labor market experiments in macroeconomics and public finance.

\section{Experimental Gift-Exchange Labor Markets}

\subsection{Common Features Across Experiments}

Most experiments described in this section are based on similar implementations of the gift-exchange game. At the beginning of an experimental session, subjects are randomly assigned the roles of either firms or workers and they keep their role during the whole session. In the first stage, firms offer a contract specifying the wage. In some experiments workers have to accept what is offered while in others the contract may be rejected in favor of some outside option. In the second stage, workers decide on the level of effort they want to exert, which is costly to them but profitable to the firm. Often this two-stage game is repeated for several periods with the same or changing firm-worker pairs. In the wage formation (first) stage commonly one of three institutions is explored: bilateral bargaining, one-sided auction, or double auction markets.

In bilateral bargaining, a firm is exogenously and randomly matched with a worker either only at the beginning of the experiment or at the beginning of each period. In each period, a firm proposes a wage only to the worker with whom it has been matched.

In one-sided auction markets, firms publicly announce their wage offers, which can be accepted by any worker. Firms are allowed to revise their offers, often according to an improvement rule, until they are accepted or the market closes. Workers cannot make counteroffers. In double auction markets both, firms and workers, can submit and accept wage offers at any time during the trading period. In both market institutions, after a wage contract is concluded the involved firm and the worker are removed from the market for that trading period. Firms and workers who do not strike a contract receive some reservation earnings. In the most common implementation at most one contract per period can be concluded and often there is an excess supply of labor.

In the basic implementation of the second stage, the worker's costly effort choice, firms can neither punish nor reward workers for their choice. Further, all institutional features are public knowledge, including the number of firms, workers, and periods, the matching mechanism, the feasible effort levels, 
the costs of effort, the wage range, and the payoff functions. Wage offers may be public or private depending on the chosen market institution, but a worker's effort choice is always private information. That is, it is only revealed to the firm with which the worker has concluded a contract. Identities of trading partners are usually not revealed.

\subsubsection{Effort Levels and Cost Function}

Most studies reviewed here adopt one of two effort-cost schedules. In one version, costs $c(e)$ are increasing and convex in effort $e$ as, for example, in Table 1. In the other common version costs are linear in effort.

Table 1. Effort Levels and Costs of Effort.

\begin{tabular}{lcccccccccc}
\hline \hline Effort $e$ & 0.1 & 0.2 & 0.3 & 0.4 & 0.5 & 0.6 & 0.7 & 0.8 & 0.9 & 1 \\
Cost $c(e)$ & 0 & 1 & 2 & 4 & 6 & 8 & 10 & 12 & 15 & 18 \\
\hline
\end{tabular}

\subsubsection{Payoff Functions}

Regarding the payoff functions for firms and workers there are also two commonly implemented versions. Firms' payoff function is often a version of

$$
\pi^{F}=(v-w) e+k
$$

or

$$
\pi^{F}=v-w+k
$$

where $v$ denotes an exogenously given redemption value, $w$ the wage, $e$ the effort chosen by the worker, and $k$ some lump-sum transfer.

Workers' payoff function is mostly implemented as the difference between the accepted wage, $w$, the incurred effort cost, $c(e)$, and some fixed costs or transfer $c_{0}$ :

$$
\pi^{W}=w-c(e)-c_{0}
$$

The parameter values are chosen such that under the assumption of material self-interest workers will never choose an effort level higher than the minimum effort, irrespective of the accepted wage. Rational and profit-maximizing firms will anticipate this and, hence, offer the lowest positive wage satisfying workers' participation constraint. The predicted outcome is thus low wages, low efforts, and most importantly no positive relationship between wages and effort levels. Alternatively, the gift-exchange hypothesis (Akerlof, 1982) postulates a positive correlation between wage offers and effort provision and, in consequence, higher than minimum wages and higher than minimum effort levels. ${ }^{1}$

\subsection{Fundamental Results}

This section reviews some of the seminal gift-exchange labor market experiments and summarizes by now well-established empirical results on the wage-effort relation. First, early experiments are presented, where the gift-exchange hypothesis is tested in one-shot encounters. In these experiments firms and workers meet essentially only once, leaving no or little room for reputation concerns. Next, we survey papers where reputation may play a role due to repeated interactions between the same firm-worker pair. 
Finally, we present evidence on the role of negative reciprocity and wage attribution on the functioning of gift-exchange labor markets.

\subsubsection{Gift-Exchange in One-Shot Interactions}

Evidence on the presence of gift-exchange in experimental labor markets dates back to Fehr et al. (1993) who have been the first to use the above described setup to test for the validity of the fair wage-effort hypothesis. They model the labor market as a one-sided auction and frame it in good market terms: buyers and sellers who choose prices and quality, respectively. The authors observe clear evidence in favor of the gift-exchange hypothesis as wages and efforts are strongly positively correlated. Consequently, wages and effort are clearly above their respective minimum level and also do not show any tendency to decline with repetion.

In a second paper, Fehr et al. (1998b) check whether observed high wages are due to firms' unconditional preference to pay high wages or due to workers' willingness to reciprocate high wages with high effort levels. They compare two different treatments (reciprocity treatment and control treatment), which differ only in that in the control treatment effort levels are exogenously fixed at the lowest effort level, eliminating opportunities for gift-exchange, whereas in the reciprocity treatment workers are free in their effort choices. Since subjects participated in both treatments, it could be tested if the same firms change behavior or not. It is found that the very same firms which pay rather high wages when workers can reciprocate significantly lower their offers when the effort is fixed by the experimenter. This shows that it is mostly not firms' unconditional preference to pay high wages but that those are induced by experienced and anticipated low-effort responses to low wages and, consequently, low profits.

Fehr et al. (1998a) are the first to study the effect of competition among workers on wages. They conduct three different treatments: a one-sided auction, called gift-exchange market, a bilateral giftexchange (BGE), where firms and workers are exogenously matched, and a complete contract market $(\mathrm{CCM})$, where the maximum effort level is exogenously enforced. By comparing the wages in CCM and gift-exchange market it could be assessed whether the high wages in the latter as found by Fehr et al. $(1993,1998 b)$ are indeed attributable to gift-exchange. Comparing wages in bilateral gift-exchange, where competition in the labor market cannot play any role, with those in gift-exchange market shows to what extent competition affects wage levels. The authors find that high wages are reciprocated by high efforts, both in gift-exchange market and bilateral gift-exchange, with no tendency for this positive correlation to decline over time. Importantly, already after a few periods wages in gift-exchange market and bilateral giftexchange coincide, indicating that labor market competition does not affect wage formation. However, wages in gift-exchange market are significantly above wages in CCM, where firms constantly try to stipulate lower wages. This indicates that in gift-exchange market firms anticipate workers' reciprocal responses and that payment of noncompetitive wages generates higher profits. In consequence, firms are unwilling to enforce low wages when there is room for workers to reciprocate with effort.

\subsubsection{Gift-Exchange and Reputation}

Employment relationships are seldom characterized by one-shot transactions. Rather employers and employees often interact repeatedly over time, which creates incentives for reciprocation, even for materially selfish workers provided that they can expect (future) material gains from it. This potential reputation effect has been first explored in Gächter and Falk (2002). They compare behavior in a one-shot (OS) treatment and a repeated game (RG) treatment, where the same firm-worker pairs interact repeatedly. In line with earlier results they find that wages and effort levels are clearly above their minimum values. Importantly, for similar wages in the two treatments, workers are more reciprocal in RG than in one-shot: this shows that repeated interaction and reputation incentives strengthen the positive wage-effort relation. 
An individual level analysis further suggests that even selfish workers have a strong incentive to act reciprocally, because providing high effort in response to high wage offers improves reputation and gives access to attractive wage offers.

Brown et al. (2004) implement three treatment conditions in order to investigate how contractual incompleteness affects the nature of market interactions and the formation of relational contracts. In all treatments, the market for contracts is organized as a one-sided auction where contracts consist of a wage, a desired effort level, and the firm's ID number. In the complete contracts treatment (C), a firm's desired effort level is exogenously enforced by the experimenter. Under the incomplete contract condition (ICF), the worker can choose any effort in the feasible range. In both these treatments, firms and workers have fixed ID numbers throughout the whole experimental session implying that a firm can address its contract offer to a specific worker in consecutive periods. In the third incomplete contract treatment (ICR), firms and workers are randomly assigned a new ID number in each period, ruling out the possibility of entering long-term relations. In each trading period firms can make private or public offers, where private offers are only transmitted to the worker with whom a firm wants to trade while public offers can be observed and accepted by any worker in the market.

The authors find that in $\mathrm{C}$ traders are indifferent to their trading partners' identities, whereas firms strongly prefer to trade with the same worker over many consecutive periods in ICF. In the former case, contract offers are mostly public offers and the majority of trades take place in one-shot (OS) transactions. In contrast, in the latter case, trades are usually privately initiated and bilateral relationships emerge. In C firms pay relatively low wages and appropriate the largest share of the gains from trade, whereas in ICF they pay high wages and earnings from trade are distributed rather equally. Effort is significantly higher in ICF, while in ICR, average effort drops and workers choose the minimal effort level in most cases. An important insight from this paper is that firms use high wages, together with the threat of firing, to discipline selfish workers. They adopt a policy of contingent contract renewal where relatively high effort levels are rewarded with a new contract, while relations with workers providing low effort are terminated with high probability.

Brown et al. (2012) implement the same three treatments in a market characterized by excess demand for labor, to check whether relational contracts emerge even in the absence of the unemployment threat. What they find is that bilateral relations between firms and workers do emerge in these markets, with wages and effort higher in ICF than in ICR and C, but are more difficult to be sustained over time. Stronger competition among firms and the lower number of long-term relationships do not affect market performance, though: aggregate effort in ICF is almost identical to that under excess supply of labor. A main reason for that is that higher wages due to excess labor demand induces workers to provide more effort.

\subsubsection{Gift-Exchange, Negative Reciprocity, and Wage Attribution}

Some of the results surveyed above have been questioned because they are obtained in an environment that may favor workers' opportunity to exhibit positive reciprocity, that is, by responding to high wages with high effort levels. However, negative reciprocity, the willingness to incur costs to punish unkind actions, may also have a role in the wage formation with potential opposite effects, as low effort responses to low wages may unravel into even lower wages and efforts.

To study the role of negative reciprocity, Fehr and Falk (1999) compare double auction labor markets where effort is endogenous (main treatment) to others where effort is exogenously fixed (control treatment), with excess supply of workers in both cases. What distinguishes this experiment is the implementation of a modified cost function, according to which a selfish money-maximizing worker should always choose the maximum effort level, because lower levels are more costly. Results from the main treatment show that workers indeed react to low wage offers by choosing non-maximal effort levels. This negatively reciprocal behavior leads firms to pay higher wages in the main treatment, even if workers 
underbid each other's wage offers. In contrast, in the control treatment wages tend to decrease over time and come close to the competitive equilibrium level. These findings show that firms may be reluctant to push wages down toward the competitive level, if workers have the opportunity to punish them via their effort choices. Workers' negative reciprocity generates wages that are downwardly rigid.

Charness (2004) explores bilateral gift-exchange under three experimental conditions that differ in the wage-generating mechanism. First, wages are determined by the firm, second they are generated by a draw from a bingo cage, and, third, by an assignment by a third party, the experimenter. In all cases, workers are informed whether the received wage has been assigned by either the firm or one of the external processes. In all treatments, there is a positive relationship between wages and effort levels. However, at low wages, the effort level is lower when the wage is chosen by a firm than when it is exogenously generated, suggesting the presence of negative reciprocity. That is, workers never provide costly effort when a low wage can be attributed to the firm's intention but do so when the low wage comes from an exogenous source. At high wage levels, there is essentially no difference in effort levels across treatments. ${ }^{2}$

The results from Charness (2004) suggest that the mechanism according to which wages are formed has a non-negligible impact on workers' performances. Maximiano et al. (2013) make an important step in investigating this conjecture by studying wage attribution by means of a more complex giftexchange environment, where ownership and control are separated. Specifically, owners do not directly set a worker's wage and the manager, who actually determines the wage, does not bear the full wage costs and does also not fully benefit from workers' higher efforts. The authors consider four treatments. The bilateral condition is a standard bilateral gift-exchange setting, with a firm consisting of a single ownermanager who is directly responsible for choosing the worker's wage. In the two trilateral conditions (TC0 and TC25), ${ }^{3}$ the firm is owned by a shareholder, who claims most of the firm's profit, but controlled by a manager, who chooses the worker's wage. In the fourth treatment, wages are randomly determined by the experimenter (cf. Charness, 2004). In all treatments, a gift-exchange wage-effort relationship is found. The higher the wage offered, the higher the average effort level chosen by workers, irrespective of the firm's composition and whether the manager receives part of the profits or not. Importantly, the wage-effort relationship is steepest when wages are determined by a member of the firm. The finding that the wage-effort relationship does not differ among the three endogenous treatments indicates that workers are not particularly sensitive to how ownership and control are divided within the firm, but are reciprocal toward the firm as a whole.

Table 2 shows the average wage, the average effort and the estimated wage-effort relation for some prominent papers surveyed in section 2.2.

\subsection{Gift-Exchange Labor Markets and Policy Instruments}

Despite the robustness and prevalence of gift-exchange wage-effort relationships, still relatively few experimental studies investigate policy implications of it. Among others, questions that could be asked are: Are (un)employment policies similarly (in)effective in gift-exchange and complete contract markets? Do optimal and redistributive tax policies have the predicted effects in gift-exchange labor markets? Here, we survey the experimental studies asking such important policy implications of gift-exchange in labor markets.

\subsubsection{Taxation}

Riedl and Tyran (2005) are the first to examine whether and to what extent statutory tax incidence affects the performance of efficiency-wage markets and whether Tax Liability Side Equivalence ${ }^{4}$ (tax LSE) holds in gift-exchange labor markets. Theory predicts that tax LSE also holds in gift-exchange labor markets as long as participants are only concerned with net wages and profits. Yet, if workers make their effort 
Table 2. Average Wage, Average Effort, and Gift-Exchange Relation for Selected Studies.

\begin{tabular}{|c|c|c|c|}
\hline & Average Wage & Average Effort & Gift-Exchange \\
\hline Fehr et al. (1993) & $\begin{array}{c}72 \\
{[26,126]}\end{array}$ & $\begin{array}{c}0.4 \\
{[0.1,1]}\end{array}$ & $\begin{array}{c}0.0078 \\
\text { OLS }\end{array}$ \\
\hline \multicolumn{4}{|l|}{ Fehr et al. (1998b) } \\
\hline $\mathrm{CT}$ & $\begin{array}{c}215 \\
{[210,290]}\end{array}$ & - & \\
\hline RT & $\begin{array}{c}74 \\
{[30,110]}\end{array}$ & $\begin{array}{c}0.36 \\
{[0.1,1]}\end{array}$ & $\begin{array}{c}0.0087 \\
\text { Tobit }\end{array}$ \\
\hline \multicolumn{4}{|l|}{ Falk and Gächter (2002) } \\
\hline RG & $\begin{array}{c}57.6 \\
{[20,120]}\end{array}$ & $\begin{array}{c}0.47 \\
{[0.1,1]}\end{array}$ & $\begin{array}{c}0.0111 \\
\text { Tobit }\end{array}$ \\
\hline \multicolumn{4}{|l|}{ Brown et al. (2004) } \\
\hline $\mathrm{C}$ & $\begin{array}{c}33.3 \\
{[1,100]}\end{array}$ & $\begin{array}{c}9.3 \\
{[1,10]}\end{array}$ & - \\
\hline ICF & $\begin{array}{c}40.1 \\
{[1,100]}\end{array}$ & $\begin{array}{c}6.9 \\
{[1,10]}\end{array}$ & $\begin{array}{l}0.14 \\
\text { OLS }\end{array}$ \\
\hline ICR & $\begin{array}{c}24.3 \\
{[1,100]}\end{array}$ & $\begin{array}{c}3.3 \\
{[1,10]}\end{array}$ & $\begin{array}{l}0.11 \\
\text { OLS }\end{array}$ \\
\hline \multicolumn{4}{|l|}{ Fehr and Falk (1999) } \\
\hline $\mathrm{CC}$ & $\begin{array}{c}34.96 \\
{[20,120]}\end{array}$ & - & \\
\hline \multicolumn{4}{|l|}{ Charness (2004) } \\
\hline Wage offer by employer & $\begin{array}{c}54.87 \\
{[20,120]}\end{array}$ & $\begin{array}{c}0.312 \\
{[0.1,1]}\end{array}$ & $\begin{array}{l}0.012 \\
\text { Tobit }\end{array}$ \\
\hline Wage offer by random & $\begin{array}{c}56.97 \\
{[20,120]}\end{array}$ & $\begin{array}{c}0.344 \\
{[0.1,1]}\end{array}$ & $\begin{array}{c}0.0088 \\
\text { Tobit }\end{array}$ \\
\hline Wage offer by third party & $\begin{array}{c}57.87 \\
{[20,120]}\end{array}$ & $\begin{array}{c}0.317 \\
{[0.1,1]}\end{array}$ & $\begin{array}{c}0.0085 \\
\text { Tobit }\end{array}$ \\
\hline \multicolumn{4}{|l|}{ Maximiano et al. (2013) } \\
\hline $\mathrm{BC}$ & $\begin{array}{c}61.45 \\
{[0,100]}\end{array}$ & $\begin{array}{c}2.41 \\
{[1,10]}\end{array}$ & $\begin{array}{c}0.0283 \\
\text { RE }\end{array}$ \\
\hline $\mathrm{TC} 0$ & $\begin{array}{c}67.24 \\
{[0,100]}\end{array}$ & $\begin{array}{c}2.77 \\
{[1,10]}\end{array}$ & $\begin{array}{c}0.0378 \\
\text { RE }\end{array}$ \\
\hline TC25 & $\begin{array}{c}49.29 \\
{[0,100]}\end{array}$ & $\begin{array}{c}2.76 \\
{[1,10]}\end{array}$ & $\begin{array}{c}0.0039 \\
\text { RE }\end{array}$ \\
\hline BCexo & $\begin{array}{c}64.5 \\
{[0,100]}\end{array}$ & $\begin{array}{c}3.07 \\
{[1,10]}\end{array}$ & $\begin{array}{c}0.0118 \\
\text { RE }\end{array}$ \\
\hline
\end{tabular}

Note: Brackets indicate the range of possible values; the variable "gift-exchange" measures the increase of effort for an infinitesimal increase in wage; OLS $=$ ordinary least square regression; Tobit $=$ Tobit regression; $\mathrm{RE}=$ random effects regression. 
choices on the basis of gross wages and consider taxation as exogenous to the gift-exchange relation, tax LSE breaks down. This alternative hypothesis is suggested by a study of Kerschbamer and Kirchsteiger (2000) who show that tax LSE may break down in bilateral bargaining environments.

In a one-sided auction environment, Riedl and Tyran (2005) implement two treatments, differing in the sequence of two distinct tax regimes. In one regime the tax is levied on firms while in the other regime workers are obliged to pay the tax. Each regime lasts for 16 trading periods.

The main results are that gift-exchange emerges and that tax LSE holds in the gift-exchange labor markets under study. None of the analyzed variables, net wages, worker efforts, and net earnings, significantly differs between regimes, not even in the short run. Net wages are almost the same in both tax regimes right from the very beginning. Similarly, workers' earnings as well as firms' profits are not different across nor within treatments, thus clearly supporting tax LSE.

\subsubsection{Competition and Wage Rigidity}

A main implication of gift-exchange is that wages may be downwardly rigid because firms have no incentive to lower wages as this would lead to low performance of workers and, hence, to low profits.

As mentioned above evidence for that has been provided by Fehr and Falk (1999) who investigate wage formation in a double auction market, which is considered as particularly competitive (see, e.g., Davis and Holt, 1993). Brandts and Charness (2004) analyze whether gift-exchange is affected by the relative number of firms and workers on the market. They implement a market with excess supply of labor and a market with excess supply of firms, with wage formation in a one-sided auction. They find that wage and effort are positively correlated and that this relation is not affected by competitive pressure. Specifically, wages do not significantly differ across treatments and are generally quite high. Hence, overall the gift-exchange relation appears to be robust to increased competition on the labor market.

\subsubsection{Minimum Wage Legislation}

Experimental evidence shows that changes in the level of the minimum wage strongly affect what is perceived by individuals as a fair wage, causing important effects on reservations wages, actual wages, and employment levels.

Brandts and Charness (2004) are the first to study the effect of a minimum wage on behavior of firms and workers in a gift-exchange context with excess supply of workers. They find that the imposition of a minimum wage has an adverse effect on effort exerted by workers. Although the relationship between wage and effort remains significantly positive, the impact on effort provision is negative. At all wages effort levels are lower with than without a minimum wage.

Falk et al. (2006) look at the effects of a minimum wage in an economy with complete contracts, where workers provide either zero effort, if they reject a wage offer, or automatically provide maximum effort, if they accept a wage offer. They find that, when minimum wages are introduced, workers' endogenous reservation wages increase to above the level of the minimum wage. This suggests that being paid exactly the minimum wage is viewed as unfair by workers. In addition, the introduction and removal of a minimum wage have asymmetric effects. If existing minimum wages are removed reservation wages only marginally decrease and remain substantially above those prevailing before the introduction of the minimum wage.

Owens and Kagel (2010) find partly contrasting results. They observe that the introduction of the minimum wage results in an increase in average wages but also that dropping the minimum wage leads to a decrease in both average wages and average effort. When a minimum wage is introduced the effects on effort levels differ depending on the wage rate. At lower wage rates and, in particular, in the neighborhood of the minimum wage, a reduction in effort is detected, while no systematic effects on effort levels are found for higher wages. 
Overall the evidence of the effect of minimum wages on provided effort is mixed. Importantly, however, the surveyed studies show that on the one hand, the minimum wage increases average wages inducing reciprocal workers to exert more effort. On the other hand, the minimum wage may alter subjects' fairness perceptions perhaps due to a reference point effect (Kahneman and Tversky, 1979; Abeler et al., 2011). Consequently, wages considered fair when there is no minimum wage tend to be perceived as less fair once there is a minimum wage. The net effect of the minimum wage on effort turns out to be ambiguous and depends on the relative size of these two counteracting effects (Fehr et al., 2009).

\subsubsection{Sick Pay}

Duersch et al. (2012) experimentally study the interaction of sick pay provision and gift-exchange between firms and workers. The authors modify the standard gift-exchange design to specifically test two hypotheses: the "gift-exchange hypothesis," which claims that workers uniformly reciprocate sick pay, and the "selection hypothesis," according to which sick pay favors the matching between those firms who offer sick pay and those workers who appreciate and reciprocate it. In each of 10 periods, employers have to choose from a menu of five contracts each consisting of a wage, $w$, which is paid if the worker shows up for work, and a sick pay, $s$, which is paid otherwise. Workers' lowest effort is equivalent to (pretending to) being sick and not showing up at the workplace. Importantly, the lowest effort may also happen for reasons outside the workers' accountability. Firms, however, can only verify if workers show up or not. Two main treatments are compared. In treatment $M$ (Monopsony) firms and workers are exogenously and anonymously matched in each period. In treatment $S$ (Selection) firms compete for workers and are given the possibility of hiring more than one worker.

Gift-exchange results are replicated. Moreover, offering sick pay also increases effort. However, the experimental data also show that offering sick pay contracts is not always the most profitable option for firms. In $M$ firms sometimes even suffer losses. Interestingly, when firms have to compete for workers they earn the highest profit when choosing a contract that offers only a partial sick pay. Firms realize this and most frequently choose the contract consisting of a partial sick pay. In both treatments, sick pay contracts induce self-selection and attract more reciprocal workers. In conclusion, in the presence of gift-exchange the effectiveness of sick pay is driven by competition in the labor market.

\subsubsection{Deferred Compensation}

Huck et al. (2011) experimentally test Lazear's (1979) model of deferred compensation and examine the relationship between a firm's wage offer and worker's effort provision in a three-period game. ${ }^{5}$ Four treatments are implemented.

In the main Full Commitment Treatment (FCT), firms can fully commit to future wage offers. In FCT results are mixed for both, firms and workers. Deferred compensation is observed but not all firms offer the predicted wage pattern and some workers shirk although they are incentivized not to do. In order to better understand that pattern, the authors conduct two control treatments. In the No Commitment Treatment (NCT), firms can only make non-binding promises about future payments. In the computer firm treatment (CFT), firms' wage offers are generated by a computer in order to control for the effect of outcome inequality. When there is no commitment device workers' effort and efficiency are low, as predicted. Workers do not believe wage promises and do not reciprocate to promised high future wages. Actual wages are indeed lower than promised ones. Nevertheless, there is evidence for gift-exchange but mainly within a period. Therefore, the authors conclude that the best strategy to induce high effort is not to offer a low wage early and promise a high wage later but offer a high wage right at the beginning. In the Reputation Treatment (RT), firms' past history on wage promises and actual wages is made available 
to workers, in order to check for reputation effects. The authors find that actually paying high wages to old workers has indeed a reputation effect and reputation may work as a commitment device.

\subsubsection{Gift-Exchange, Incentive Schemes, and Contract Enforcement}

Laboratory gift-exchange experiments show that reciprocity is effectively increasing worker effort when contracts are incomplete. In the field, also material incentives are used to mitigate the enforcement problem. Therefore, the question of how explicit performance incentives and gift-exchange interact with each other has been subject of several studies.

Fehr et al. (1997) conduct three treatments involving competitive markets with more workers than firms. In each treatment, firms specify a wage, a desired effort level, and a fine imposed if a worker is detected shirking. In the no-reciprocity-treatment (NRT) contract terms are exogenously enforced by the experimenter; in the weak-reciprocity-treatment (WRT) workers who accept a contract choose an effort level, and a random device determines whether the firms are able to verify shirking; the strongreciprocity-treatment (SRT) has an additional third stage in which firms can also respond reciprocally, by costly rewarding or punishing workers after they observe actual effort choices.

The results from WRT show that firms' behavior is affected by reciprocity considerations, as the number of generous offers is significantly higher than in the NRT. Nevertheless, shirking is also quite prevalent. In SRT firms demand and succeed in enforcing much higher effort levels than in WRT. They punish workers who shirk and reward both those who provide the desired or more effort. In response workers reciprocate high wages with high efforts. This leads to a higher aggregate monetary payoff, meaning that both workers and firms are better off in SRT.

Fehr and Gächter (2002) examine the possibility that explicit incentives may create a hostile atmosphere of threat and distrust undermining reciprocity-based extra effort. They conduct a gift-exchange experiment under two treatments, a trust treatment (TT), which resembles a standard gift-exchange game under the one-sided auction trading rules and an incentive treatment (IT) where firms can punish shirking workers.

In TT firms offer higher wages and demand higher effort levels than in IT, resulting in higher actual average effort. The authors observe that the lower effort levels in IT are not caused by lower wage offers but that low wages are a response to the reduction of the workers' willingness to reciprocate. Further, the data show that efficiency is lower in IT, due to the reduced effort levels. The authors conjecture that the negative incentive effect is due to framing the material inventive as punishment, which workers may perceive as unkind. To test this, an additional bonus treatment (BT) where a shirking worker, instead of paying a fine, does not receive a bonus if caught shirking, is conducted. The incentive structure is exactly the same in IT and BT. Nevertheless, large behavioral differences are observed in IT and BT. With the material incentive framed as bonus, effort levels are significantly higher than when it is framed as punishment.

Fehr et al. (2007) compare the performance of three types of contracts. In the incentive contract the principal offers a wage, a required effort level, and a fine paid in case the agent is caught shirking. If the principal invests in a verification technology, agents' effort choices are observed with the exogenous probability $p=1 / 3$. In the trust contract, the principal offers a fixed wage to the agent and asks for high effort in return. Lastly, the bonus contract is similar to the trust contract, except that the principal announces that $\mathrm{s} / \mathrm{he}$ might pay a bonus if the agent exerts more effort than required. The authors conduct a bilateral gift-exchange experiment with two treatments. In the trust-incentive treatment (TI) principals could choose between the trust contract and the incentive contract and in the bonus-incentive treatment (BI) all three contracts could be chosen. In TI it is found that incentive contracts are chosen by most principals and increasingly preferred over time as they perform better from the firm's perspective. Workers' effort levels and principals' payoffs are higher with incentive contracts than with trust contracts. In stark contrast, in the BI treatment bonus contracts are chosen much more often than the incentive contracts 
and the trust contract is never chosen. Hence, on the one hand, in TI fairness concerns are not powerful enough to contradict standard theory prediction that incentive contracts are preferred to trust contracts. On the other hand, when a non-binding promise to pay bonuses is introduced, the results contrast with what standard theory postulates.

In a subsequent paper, Fehr and Schmidt (2007) wonder whether combining a bonus and an incentive contract helps improving efficiency. Principals can choose between a pure bonus contract and a combined contract, which therefore offers both a fine paid in case of detected shirking and a voluntary bonus. Still, the authors find that the vast majority of principals prefer the pure bonus contract, which also turns out to be more efficient. These results seem to support the idea that, in many cases, explicit negative incentives may crowd out intrinsic motivation, as agents might perceive a fine as a hostile act and the choice of monitoring the agents as a signal of distrust.

Eriksson and Villeval (2012) study whether symbolic but costly reward ("respect" in the authors' words) for high effort affects gift-exchange. They find that the majority of employers do not send symbolic rewards. More symbolic rewards are sent when there is competition on the labor market than when it is balanced and they are mainly used to initiate longer-term relationships. Interestingly, receiving rewards induce higher efforts only when the market is balanced.

Fehr et al. (1996) study incentive effects on efforts in a different environment. Specifically, they test whether the predictions of the shirking version of the efficiency wage hypothesis (Shapiro and Stiglitz, 1984), namely that higher wages and lower effort requirements reduce shirking, are borne out by the data. In the Efficiency Wage Experiments (EWE) firms with different production technologies offer contracts consisting of a wage, a required effort level, and a penalty levied on the worker in case caught shirking. The results are then compared to a Market Clearing Experiment (MCE), where the incentive to pay efficiency wages is removed by allowing the imposition of a higher penalty. In the EWE it is observed that firms make a rational and selfish use of penalties, meaning that the great majority of the chosen penalties meet the standard theoretical predictions. However, wage offers and demanded effort levels tend to lie below the predicted values, suggesting that firms' choices might be affected by risk aversion. In the MCE the market converges to the predicted values. Most importantly, the authors find support for the efficiency wage hypothesis as an increase in wage offers reduces the probability of shirking and firms try to pay job rents to induce workers not to shirk. Finally, it is shown that the existence of efficiency wages leads to involuntary unemployment.

\subsection{Robustness and Extensions of Gift-Exchange Labor Markets}

Gift-exchange labor market experiments have been conducted under many environmental conditions and the strong positive relationship between wage and effort has been confirmed by a large number of papers. There are, however, some conditions where gift-exchange may break down. The experiments summarized in this section propose extensions of the basic gift-exchange game design and try to assess whether and to what extent changes in the environmental features affect gift-exchange.

\subsubsection{Gift-Exchange, Multi-Worker Firms, and Social Comparisons}

The external validity of experimental results gathered in relatively simple environments is a challenge for experimental economics in general and for gift-exchange labor market experiments in particular. For instance, the mostly used implementation of gift-exchange markets, where employment relationships involve one employer and one employee, may limit the validity of results for cases where employers can hire more than one worker.

Maximiano et al. (2007) compare a standard one-employer-one-worker (1-1) bilateral gift-exchange game with one in which each firm has four workers (1-4). In the latter case, the firm has to pay the same 
wage to all workers, who then simultaneously decide how much effort to provide without knowing the effort choices of their co-workers. In both treatments, workers choose, on average, a higher effort level the higher the offered wage and the difference between treatments is small and statistically not significant. Hence, overall the wage-effort relation is robust to an increased number of workers within a firm.

The previous paper is mainly concerned with the relationship between agents at different levels in the firm hierarchy. Charness and Kuhn (2007) examine how the horizontal relationship between workers and the observation of each other's wages may affect effort choices. They match two workers with different productivity levels (high and low) with one firm. Workers know that their productivity is different from their co-workers' but they do not know the direction of this difference. Firms can offer their workers different wages. The authors also vary, in a within-subjects design, whether wage offers are public (both workers know both wages) or private (workers know only their own wage). The data show that when a co-worker's wage is secret workers' effort choices respond very strongly to their own wage. Interestingly, the same holds when workers are informed of their co-workers' wage before choosing their own effort. Hence, workers seem to be mainly concerned with their own wage offer and horizontal comparisons are either not important or wage differences are perceived as justified because of the productivity differences.

Gächter and Thöni (2010) analyze horizontal pay comparison effects when workers are equally productive. In contrast to Charness and Kuhn (2007), they find that a worker who is paid less than a co-worker significantly reduces his/her effort relative to a situation where equal wages are paid. Gächter and Thöni (2010) further analyze whether the observed pay comparison effects actually come from wage differences or are due to an aversion to intentional wage discrimination. In an additional treatment, a random device chooses workers' wages on behalf of firms. It turns out that disadvantageous wage discrimination does not result anymore in reduced effort levels and, hence, intentionality is the source of reduced efforts in case of unequal wages.

Gächter et al. (2012) go a step further and investigate whether the possibility to compare both, pay and effort, influences reciprocal behavior. In a three-person gift-exchange game, the employer chooses a wage, which can be different for different workers. In the experiment employees first observe both wages and then choose sequentially an effort level. The worker who moves second (Employee 2), therefore, also receives information about the co-worker's effort choice. The authors find that in this setting pay comparisons do not affect effort choices. However, for a given wage combination, a worker's effort depends on the co-worker's effort decision. Employee 2 exerts high effort if Employee 1 does so and tends to choose low effort if the co-worker also chooses low effort. Hence, on average reciprocity toward the employer is weakened when effort comparison is possible.

Nosenzo (forthcoming) studies pay comparison effects in a gift-exchange game where one employer is matched with two symmetric employees, and compares effort choices under three treatments: in the "pay secrecy" treatment each employee only knows his/her own wage; the two "public wages" treatments, where both wages are known to both employees, differ in how wages are determined. In one treatment the employer can choose both wages, while in the other one wage is set exogenously. The data show that information about co-workers' wages can be detrimental for effort provision. In the pay secrecy treatment effort levels are higher than in the other two treatments because with public wages employees who are paid less exert less effort. Interestingly, this holds even when co-workers' wages are chosen exogenously.

In Abeler et al. (2010), two agents are matched with one principal who chooses a wage only after having observed the effort simultaneously chosen by the agents in the first stage of a gift-exchange game. In one treatment the principal has to pay the same wage to both agents, while in a second treatment she can set different wages for the two agents. The authors find that in the equal wage treatments effort levels are significantly lower than when agents are paid individually, suggesting that agents perceive equal wages for unequal performance as unfair. In the individual wage treatment principals seem to anticipate that and pay higher wages to agents who exert higher effort. Moreover, when wages are set equal by the employer, employees who initially work hard tend to reduce effort to the level of their low-performing 
co-workers. The opposite occurs when workers are paid individually: those workers who initially exert low effort align with the high performers.

Siang et al. (2010) also test for horizontal comparisons in a bilateral gift-exchange game, under both random and fixed matching, where workers are provided with either quantitative or qualitative information about the average wage in the market. ${ }^{6}$ Overall, it is found that information about average wages has a decreasing effect on both wage and effort in the random-matching treatments, and the opposite effect under the fixed-matching protocol.

\subsubsection{Framing}

Charness et al. (2004) investigate whether providing experiment participants with a comprehensive payoff table has an effect on gift-exchange. They run a standard gift-exchange game under two different conditions. In both conditions subjects are given the payoff functions and in one treatment subjects are, in addition, given a complete payoff table reporting firms and workers' payoffs for all combinations of wages and effort. The authors find that the provision of such a table, although superfluous for subjects to be able to compute payoffs, does affect behavior. Gift-exchange is observed in both treatments but the inclusion of the payoff table decreases wages and effort. Further, with the payoff table the wage-effort relationship seems to be weakened over time, especially toward the end of the experiment suggesting strategic effort choices. The authors propose two main explanations for the lowered gift-exchange but leave the ultimate reason open. On the one hand, working through the table and focusing on it may have led workers somehow to regard their effort choices and firms' wage decisions as not linked to each other. On the other hand, the payoff table might have made the distributional consequences more salient, as firms' marginal benefit resulting from an increased effort decreases as wage increases, which might induce lower effort.

\subsubsection{Stake Levels}

Fehr et al. (2002) study the effect of high stakes on gift-exchange. They conduct two treatments of the gift-exchange market a normal-stake condition and a high-stake condition, where in the latter the stake level was 10 times higher than in the normal-stake condition, and (Russian) subjects' earnings amounted on average to up to three monthly incomes. The introduction of high stakes does not weaken the wageeffort relationship. Wages are above the competitive level and quite similar for normal and high stakes. The impact of increased stakes on effort is negligible as well. A comparison of behavior under normal stakes with Austrian subjects show that the reported results are not due to Russian subjects' characteristics. Overall, the results indicate that market institutions are more important in shaping behavior than stake size.

\subsubsection{Market Size}

The issue of how market size might affect behavior in a gift-exchange environment is addressed in Brandts et al. (2010). In the small market there are 7 traders ( 5 workers and 2 firms), while the large market has 21 trading agents (15 workers and 6 firms). In each market trades occur through two different market institutions: double auctions (DA) or bilateral negotiations (BN). The experiment lasts 30 periods in which during the first 10 rounds, subjects trade only through DA. In the successive 20 periods, at the beginning of each period, firms choose whether to enter the DA or privately negotiate with a worker. The worker, in turn, indicates whether or not s/he is willing to enter the BN. Thereafter, the game proceeds with wage offers and subsequent effort decisions. The authors report that gift-exchange is robust to the variation of the number of traders in the market. In both treatments effort and wages are positively correlated and wages and efforts in $\mathrm{BN}$ are higher than in DA. In both treatments aggregate surplus is considerably 
higher in periods $11-30$ (when DA and BN coexist in the markets) than in the first 10 periods (with only DA). Hence, the market institution is more important in shaping behavior than the market size.

\subsubsection{Transparency}

In many employment relationships the amount of effort exerted by the workers is not perfectly observable by the employer, a factor that is ignored in standard gift-exchange experiments. The question arises if workers would still be reciprocal in a situation where hidden actions are possible and, consequently, if it is still profitable for firms to offer generous wages.

Irlenbusch and Sliwka (2005) address this issue by investigating how transparency of effort choices affects gift-exchange. In their experiment, a firm's payoff is given by the sum of a worker's effort and a random component. Two treatments are conducted. In the revealed-effort treatment, firms are perfectly informed about both components of their payoff, whereas in the hidden-effort treatment, firms only observe their payoff without any further detail. Their results show that the positive wage-effort relation is present in both treatments, but it is much stronger in the revealed effort treatment. When exploring the results in more detail the authors find that actual effort levels are similar across treatments, but that wages in the hidden effort treatment are higher. The hidden effort treatment is also characterized by much more heterogeneity in agents' behavior. It seems that some agents take advantage of the principal not being able to observe their effort while others are willing to exert even more than the efficient effort level in order to signal their willingness to reciprocate.

\subsubsection{Subject Pool}

Hannan et al. (2002) conducted two experiments with two different U.S. subject pools, MBAs and undergraduate students to explore the effect of work experience. They also compared their behavior to that of Austrian students in Fehr et al. (1998b) in order to investigate whether characteristics of the U.S. society (e.g., a more individualistic approach to work) leads to different results in terms of gift-exchange. The implemented gift-exchange labor markets consist of one-sided auctions and firms were either of high or low productivity. When comparing U.S. students, MBAs, and Austrian students, the authors find that all three subject pools exhibit reciprocal preferences, but that U.S. students are less reciprocal than MBAs and Austrian students. Similarly, MBAs' wage offers are found to be considerably higher than those of U.S. students. In order to explore whether U.S. students' weaker gift-exchange is due to not being familiar with gift-exchange labor markets, the authors conduct another treatment where firms have to submit also a desired effort level. In comparison to the first experiment U.S. students exert more effort, which suggest that different work experiences of undergraduates and MBAs may account for differences in their effort responses.

\subsubsection{Gift-Exchange in Field Experiments}

Some papers study gift-exchange in the field and provide evidence that social preferences identified in the laboratory map into fieldwork environments.

Gneezy and List (2006) hire people to perform two real-effort tasks, one involving work in a library and the other involving door-to-door fund-raising. In both cases, the participants know that it is a one-time employment. Two treatments per task are conducted. In both treatments a fixed wage per hour is promised. In the first one the promised wage is paid (noGift) and in the second, after the task has been explained, participants are told that they will be actually paid a higher wage (Gift). Consistent with the laboratory evidence, in the early hours of the task higher wages are reciprocated by higher effort levels, as effort in 
the Gift treatment is markedly higher than in the noGift treatment. This effect, however, vanishes over time. After a few hours, effort levels in the two treatments are statistically indistinguishable.

Kube et al. (2012) analyze how strongly workers reciprocate monetary and non-monetary gifts with higher productivity in a real-effort task. They hire students to enter data into a computer. In the benchmark treatment all students are paid an announced wage. In the cash treatment participants receive a monetary gift, while in the bottle treatment they are given a thermos bottle of equivalent monetary value. They also run additional control treatments. In one of them, the bottle's market price is explicitly mentioned, to rule out the possibility that workers might overestimate its market value. In the choice treatment, conducted to elicit preferences for receiving cash or the bottle, subjects can choose between the bottle and the money. Finally, in the origami treatment that is run to test whether the time and effort invested in the provision of gifts matter, the firm gives the workers money in the form of an origami.

The results show that the nature of gifts determines the strength of reciprocal behavior. The cash gift has only a statistically insignificant impact on workers' productivity, while the bottle starkly increases workers' performance and the effect remains large throughout the experiment. This result is closely replicated in the treatment where subjects are informed about the price of the bottle. Further, when workers can choose between gifts, almost all of them opt for the cash gift and workers' output is the same than in the no choice bottle treatment and, thus, higher than in the no choice money treatment. This suggests that time and effort the firm spends for a gift matter for the workers. Intriguingly, the data show that workers reciprocate a money gift of the same value as in the cash treatment but presented in origami form with an output level that is $30 \%$ higher.

In Kube et al. (forthcoming) workers are hired by a university library to catalog books. In the baseline treatment, workers are paid the announced wage. In two other treatments, workers are informed, right before performing their task, that they would be paid either less or more than announced, respectively. They find that, while unexpected wage cuts severely and persistently reduce productivity, analogous wage increases do not lead to higher output levels.

Hennig-Schmidt et al. (2010) hire students for updating a database. Next to the baseline treatment, where all workers are paid the same wage, the authors perform some treatments where workers receive an unexpected pay raise and some others where workers are also informed about the wage increase of a peer group.

They observe that neither increases in the own wage nor information on peers' wages seem to affect workers' effort. Hence, contrary to most laboratory and other field experiments no positive wage-effort relation is observed. The authors complement the analysis with a real-effort lab experiment, where employees either receive a flat wage or are exposed to an unexpected wage increase under two conditions, differing in whether the information about the employer's surplus from work effort is available or not. In the absence of surplus information there seems to be no positive relation between wage and effort. However, when surplus information is provided this relation is observed. In fact, the positive wage-effort relation is quite steep and a pay raise is profitable for employers. This result suggests that workers' being aware of the employer's surplus may be crucial for reciprocal inclinations to come into play.

\subsection{Summary}

Laboratory gift-exchange experiments have identified some broad regularities. Reputation incentives (help) discipline workers and induce them to provide higher effort (Gächter and Falk, 2002; Brown et al., 2004, 2012). Effort responds to the mechanism underlying the wage formation process, at least at low wages, with stronger reactions when (low) wages are intentional (Charness, 2004), but not to the internal composition of the firm (Maximiano et al., 2013). Effort decisions are affected by the introduction or the removal of a minimum wage. An increased minimum wage may induce more effort through higher wages. However, it also shifts subjects' reference point with counterproductive effects on effort once the minimum wage is dropped (Brandts and Charness, 2004; Falk et al., 2006; Owens and Kagel, 2010). 
Evidence on the effect of explicit incentives on effort provision is a bit mixed. On the one hand, the possibility for principals to punish or reward agents seems to increase effort levels (Fehr et al., 1997). On the other hand, a decision by a principal to monitor or punish an agent can create an atmosphere of distrust and undermine gift-exchange, while nonbinding promises to pay bonuses for workers' performance can induce more effort and outperform explicit incentive contracts (Fehr and Gächter, 2002; Fehr et al., 2007; Fehr and Schmidt, 2007). In case of deferred compensation contracts, however, unenforceable promises about future payments can reduce effort (Huck et al., 2011).

Duersch et al. (2012) show that sick pay provision increases effort and attracts more reciprocal workers, even though offering sick pay contracts is a profitable option for firms only when they have to compete for workers.

Workers' effort choices can be driven by pay comparison considerations. When workers are characterized by different productivity levels wage differences do not affect effort decisions, suggesting that unequal wages for unequal performance are not perceived as unfair. A detrimental effect on effort is found when workers are all equally productive and principals offer different wages (Charness and Kuhn, 2007; Abeler et al., 2010; Gächter et al., 2012; Gächter and Thoni, 2010; Nosenzo, forthcoming). Workers' behavior can depend on co-workers' effort decisions when both effort and pay comparison information are made available (Gächter et al., 2012).

The way decision tasks are presented in the laboratory may also affect behavior. The provision of a complete payoff table, for instance, significantly decreases wages and effort (Charness et al., 2004). Impact of increased stakes on effort seems negligible (Fehr et al., 2002) and so is the effect of the number of traders in the market (Brandts et al., 2010). Effort choices may differ across subject pools (Hannan et al., 2002).

Field experiments show that gift-exchange identified in the laboratory to a large extent map into field work environments (Gneezy and List, 2006). Effort also responds to the nature of gifts as workers exert more effort in response to a non-monetary gift (Kube et al., 2012). Laboratory results that pay comparison information may have little influence on effort choices are confirmed in the field (Hennig-Schmidt et al., 2010). Finally, there is also strong field evidence of negative reciprocity when wages are cut (Kube et al., forthcoming).

\section{Experimental Labor Markets in Macroeconomics and Public Finance}

Laboratory experiments can be a valuable research tool for investigating aggregate economic phenomena. In this section we survey papers that try to assess the impact of taxation on economic performance, mainly focusing on the relation between (labor) taxation and unemployment. In a series of studies, Riedl and van Winden $(2001,2007,2012)$ show the existence of a vicious circle in the interaction between wage taxes and unemployment and suggest that shifting the tax burden from labor to sales or production can alleviate the unemployment-boosting effect of taxes. Blumkin et al. (2012) test the response of labor supply to various forms of taxation and argue that shifting taxation from labor to consumption increases labor supply, while Ortona et al. (2008) find the same effect on effort provision coming from destining taxes to insure subjects against risk and to finance public goods.

Riedl and van Winden (2001) are the first to use laboratory experiments to investigate the nexus between labor taxation and unemployment in a full-fledged economy. In particular, they study the effects of a wage $\operatorname{tax}$ (WT) system to finance unemployment benefits on the performance of an economy, mainly in reaction to tax adjustments due to a budget deficit or surplus. The economy under consideration is graphically depicted in Figure 1.

It consists of two countries, a small "home" country and a large "foreign" country, where two inputs, capital $K$ and labor $L$, and two outputs, $X$ and $Y$, can be traded. In each country, goods $X$ and $Y$ are produced in two separate sectors with the help of inputs $L$ and $K$. These inputs are, respectively, traded 


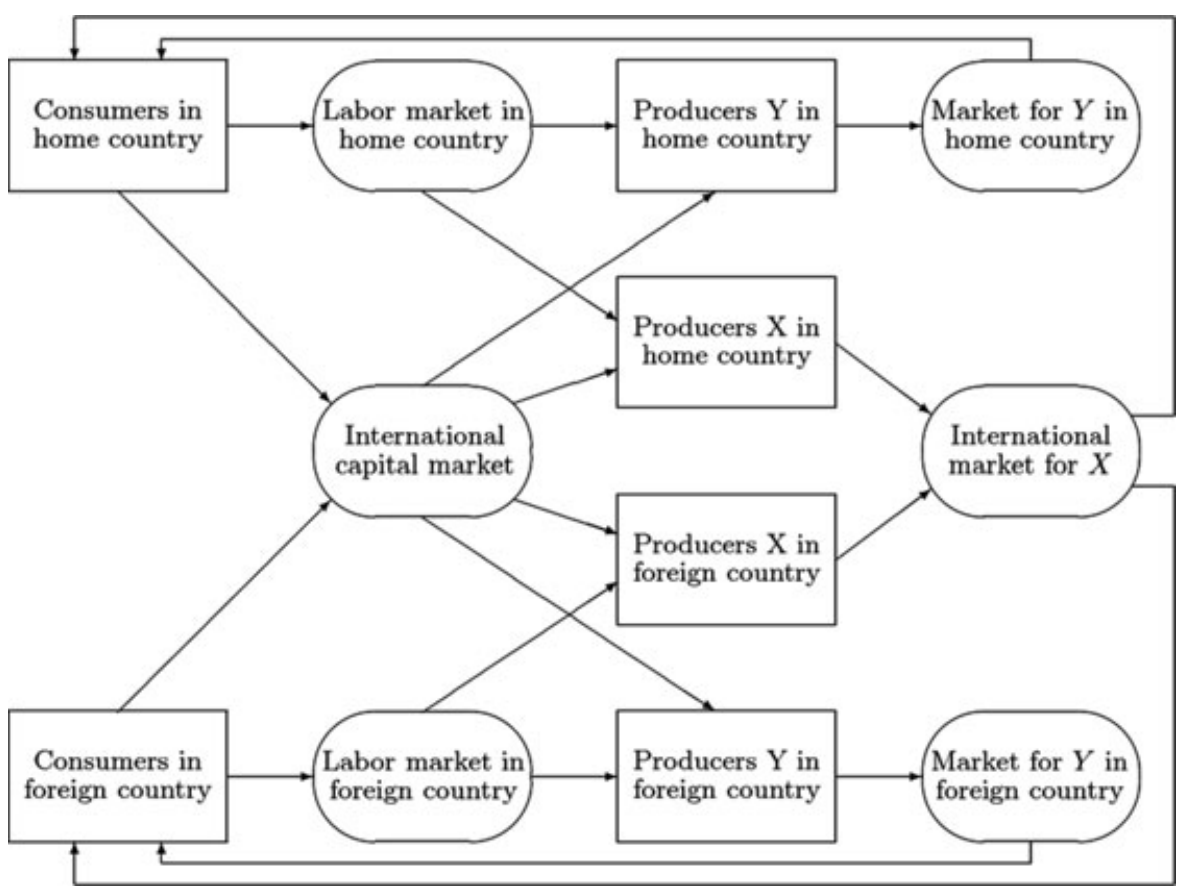

Figure 1. Flow Diagram of the Riedl and van Winden $(2001,2007,2012)$ Economy.

on a local labor market (separate in each country) and on an international capital market. Similarly, the market for commodity $X$ is international, while the market for commodity $Y$ is local. Consumers derive utility from leisure, the unsold units of labor, and the consumption of $X$ and $Y$. They are endowed with some units of labor and capital, and they obtain an unemployment benefit for each unsold unit of their labor endowment. The government finances these benefits with the help of a tax on employed labor paid by producers. Two tax regimes are implemented in each country. During the first part of the experimental session, wage taxes are held constant. During the second part, the wage tax rate is adjusted to the previous period's deficit or surplus in the government budget.

Riedl and van Winden (2001) find that in the constant tax regime both countries experience a budget deficit in all periods, which does not decrease over time. They also show that, while unemployment levels converge to the equilibrium values, nominal wages are very low in both countries. A thorough analysis of consumers and producers behavior shows that the former supply too much labor at given prices, while the latter have a tendency to employ too few labor units. This supports the so-called risk-compensated price-mechanism hypothesis, which was first detected in pure commodity markets by Noussair et al. (1995). When producers make their input decisions market conditions, prevailing at the time consumers buy their products, are usually unknown, meaning that producers face uncertainty about the revenues they can make by selling their products. Given this price uncertainty, risk-averse producers demand less labor than predicted in equilibrium. Producers and consumers combined behavior leads to an upward trend of unemployment rates and drive nominal wages down, which explains the observed budget deficit. In the dynamic tax regime, an initial considerable increase in the tax rates is observed as the previous periods' budget is not balanced. Increased taxes help to decrease the budget deficit over time. However, it comes at the cost of strong negative effects on the performance of the economy as a whole. In both countries unemployment rates increase and real GDP sharply decreases. 
In Riedl and van Winden (2007), the same setup is used to compare a closed with an international economy. Overall, the data confirm the earlier results. When the tax rate is constant, in all economies a budget deficit occurs already in early periods. The same excess supply of labor is observed, which is accompanied by producers' reluctance to buy inputs and a downward trend of wages. Together this accounts for the observed budget deficits. Once the dynamic tax regime is introduced, in all economies the deficit becomes smaller due to higher tax rates but the unemployment level increases, an effect that is due to the low employment of both factors (because of price uncertainty), which is exacerbated for labor through the wage tax.

These findings show that there exists a vicious circle in the interaction between wage tax and unemployment. This strongly suggests that shifting taxation from labor to consumption or sales may have beneficial effects on both production and employment. To explore this, Riedl and van Winden (2012) introduce a sales-tax-cum-labor-subsidy (STLS) system in the above described economy and compared it to a pure wage tax system. Two treatments are implemented. In the baseline treatment, in both the home country and the foreign country unemployment benefits are financed with a wage tax. In the alternative treatment, in the home country the wage tax system is substituted by the STLS system while the wage tax system prevails in the foreign country. Next to shifting the tax from labor to sales, in the STLS system producers also receive a subsidy equal to the unemployment benefit for each unit of labor they employ. Again, a constant tax regime is followed by a regime where the tax rate adjusts to previous periods' budget surpluses.

In the constant tax regime basically all quantities and prices as well as economic performance indicators, such as unemployment rate and real GDP, weakly converge to the theoretically predicted equilibrium values. In the small country the unemployment rate is initially higher when the STLS system is effective but tends to decrease over time, despite high sales taxes. Such a development is not observed under the wage tax system. Moreover, declining unemployment under the STLS system is associated with an increase in the budget surplus of the small country, while wage taxes are systematically accompanied by budget deficits. A similar pattern is observed for the real GDP. At the end of the constant tax regime the economies under the wage tax system face budget deficits, while budget surpluses are generated in the small country under the STLS system. Consequently, the transition to the variable tax regime is characterized by an increase in wage tax rates and by a decrease in sales taxes. The increasing tax rates in the wage tax system lead to increasing unemployment and a decrease in real GDP, while at the same time the burden from the budget deficit merely weakens. In stark contrast, in the alternative tax system the initial decline in sales tax rates reduces unemployment and boosts real GDP. In addition, the budget immediately balances and stabilizes over time. Overall, Riedl and van Winden's (2012) results show that the STLS system leads to a significantly better economic performance compared to the wage tax system. These differential results are mainly driven by producers' reluctance to incur upfront costs when they are uncertain about output prices. Importantly, producers seem to perceive uncertainty differently under the two tax systems because receiving a labor subsidy and paying taxes according to sales revenues basically gives producers the opportunity to share their risk with the government.

Blumkin et al. (2012) experimentally test the equivalence between consumption and wage taxes in a real-effort experiment where subjects have to decide how to allocate their time between labor and leisure. Subjects receive income according to their performance in a real-effort task, which they are then asked to allocate between two consumption goods. They also receive a payment for each unit of leisure consumed. The experiment consists of three parts: the first two are meant to measure and control for subjects' productivity and pretax labor-leisure preferences, respectively. Finally, in the third part in one treatment a labor income tax (IT) and in the other treatments a theoretically equivalent consumption tax (CT) is introduced.

Although theoretically equivalent, worker-consumers may work more and consume less leisure in presence of a consumption tax because of money illusion. That is, individuals may tend to think in nominal and not in real terms (for empirical evidence on money illusion see, e.g., Fehr and Tyran, 2001). 
In that case labor income taxes and consumption taxes may be perceived differently when the labor supply decision has to be made. When subjects make their decision the labor income tax is salient whereas the consumption tax is not. In consequence, subjects would work more in the consumption tax treatment than in the income tax treatment. This is indeed what the authors find. Specifically, those worker-consumers who reduce their labor supply when a tax is introduced, reduce it significantly more in the income tax treatment. In line with Riedl and van Winden (2012), this result suggests that shifting taxation from labor to consumption might potentially lead to welfare improvements, with higher utility for individuals and unchanged government tax revenues. ${ }^{7}$

Ortona et al. (2008) investigate the relation between labor supply and taxation when tax revenues are used for the production of public goods. They conduct a real-effort experiment and compare the labor supply in two states of the world. In a so-called state of nature (SN) there is a certain risk to lose part of the earned income and there are no taxes, insurance, and public goods. In a welfare state (WS) treatment, the same risk is partially insured and a proportional income tax and a public good exist. Their main result is that subjects work more under WS than under SN, which suggests that the fact that the returns from taxes are used to protect subjects against risk and provide public goods does not reduce labor supply and possibly increases it.

\section{Conclusions}

Laboratory experiments have entered labor economics and the generated results have significantly increased our knowledge on a variety of aspects. In this paper we have surveyed part of this literature and concentrated on two main areas. The first part has been devoted to the behavioral consequences of contractual incompleteness in a gift-exchange environment and in the second part more macroeconomicsoriented experiments have been presented, which mainly focus on the interaction between taxation and labor market performance.

Many employment relations are often contractually incomplete in terms of effort that workers are required to exert. In such contexts, workers' reciprocal inclinations play an important role in determining the overall surplus and profit of the firm. Laboratory experiments provide abundant evidence that a sizable share of people exhibits fairness concerns and show that reciprocity often can substitute for the absence of a formal contract enforcement device. It is now a well-established result that a positive relationship between the wages offered by firms and the effort exerted by workers exists, and that employers are actually willing to offer wages higher than the prevailing minimum to elicit higher effort.

The importance of gift-exchange in employer-employee relations has several policy implications. For instance, it has been shown that gift-exchange wages turn out to be downwardly rigid, speaking to Bewley's (1999) book title "Why wages don't fall during recessions." A consequence is that the introduction of a minimum wage may have unintended effects as it has been shown that a minimum wage may change workers' reference point of a fair wage and, hence, affect their effort provision. Further, the interaction between reciprocal inclinations and various incentive schemes has to be carefully taken into account as it does not necessarily hold that explicit incentives will have unambiguous positive effects on effort. In fact, explicit incentives may crowd out intrinsic motivation as agents may consider a fine or a punishment as a hostile act or being monitored as a signal of distrust, which may induce lower effort levels.

The positive relationship between wage and effort has been confirmed under a broad range of conditions. Nevertheless, the generalizability of gift-exchange results to more complex field environments has sometimes been questioned. Recently, scholars have started to study situations where employers can hire more than one worker, focusing in particular on the interplay between reciprocity and wage and effort comparisons. Overall also in these studies gift-exchange is observed. However, the strength of it may hinge on details of the environment. For instance, effort comparisons seem to have a stronger impact on workers' effort choices than wage comparisons. 
Also, only recently field experiments have been used to investigate gift-exchange. The empirical results of the few studies are overall verifying the laboratory results, although some find only a weak wage-effort relationship. In the field, it seems that a wage cut has stronger effects than a wage increase and nonmonetary gifts have a stronger effect than purely financial ones. An important open question is also the longevity of gift-exchange. As field experiments are almost always less controlled than laboratory setups, it is not clear yet what precisely is behind the larger variation in outcomes in field settings. It seems clear that much more research is required to filter out the institutional details that enhance or hamper gift-exchange in work relationships in the field.

The second part of this survey has been dedicated to the relatively small but important set of experiments aimed at assessing the impact of fiscal policies on the labor market and more general economic performance. These results show the existence of a vicious circle in the interaction between wage taxes and unemployment, because increasing labor taxes to balance budget deficits strongly and negatively affect overall economic performance. The findings suggest that shifting the tax burden from labor to sales or production might alleviate this effect. This research also explores conditions under which imposing a tax might foster effort provision. For instance, it is found that shifting taxation from labor to consumption increases labor supply. Overall, the number of laboratory experiments explicitly aiming at labor market questions traditionally belonging to macroeconomics and public finance is still very small. Interestingly, it is precisely these more traditional areas in economics that lately have been criticized by a skeptical public opinion. More experimental research in the laboratory (as well as the field) investigating such important questions as the perception of salience of different forms of labor taxation and the behavioral equivalence of theoretically equivalent policy interventions could be very informative for these fields too. Moreover, most of the experimental labor research takes place in a partial equilibrium setting where labor relationships and labor markets are assumed to operate on an isolated island. This has been an important and useful restriction in order to generate first clean results. Now the evidence and our knowledge have accumulated so much that time seems ripe to make the step out of the partial world and investigate more general market interactions in labor relations as it has already been done in international trade and other interactive markets experiments (Lei and Noussair, 2007; Noussair et al., 1995, 2007).

\section{Notes}

1. The gift-exchange wage-effort relationship can be rationalized by assuming outcome-based social preferences (e.g., Fehr and Schmidt, 1999; Bolton and Ockenfels, 2000), intention-based reciprocal motives (Rabin, 1993; Dufwenberg and Kirchsteiger, 2004), and a mixture of both (Levine, 1998; Falk and Fischbacher, 2006).

2. Pereira et al. (2006) also find some evidence for negative reciprocity which may be caused by a framing effect similar to those observed in dictator allocation experiments (List, 2007; Bardsley, 2008).

3. In TC0 the manager is paid a fixed wage and in TC25 condition the manager earns $25 \%$ of the firm's profit.

4. Tax LSE states that "the statutory incidence (i.e., who legally pays a tax) is irrelevant for economic incidence (i.e., who bears the tax burden)" (Riedl and Tyran, 2005).

5. In deferred compensation contracts workers are underpaid in early years of their career and overpaid in later years. Theoretically, they induce higher effort because future payments within the firm always exceed future payment elsewhere (Lazear, 1979). However, since firms can renege on future payments, the optimality of deferred contracts depends on the existence of an effective commitment mechanism.

6. More precisely, workers are informed whether the employer offers a wage which is $5 \%$ larger or smaller than the average wage across markets.

7. A related salience effect of taxation is also found for consumer goods by Chetty et al. (2009).

Journal of Economic Surveys (2013) Vol. 27, No. 3, pp. 398-420

(C) 2013 John Wiley \& Sons Ltd 


\section{References}

Abeler, J., Altmann, S., Kube, S. and Wibral, M. (2010) Gift exchange and workers' fairness concerns: when equality is unfair. Journal of the European Economic Association 8: 1299-1324.

Abeler, J., Falk, A., Goette, L. and Huffman, D. (2011) Reference points and effort provision. American Economic Review 101: 470-492.

Akerlof, G.A. (1982) Labor contracts as partial gift exchange. Quarterly Journal of Economics 97: 543569.

Akerlof, G.A. and Yellen, J.L. (1988) Fairness and unemployment. American Economic Review 78: 44-49.

Akerlof, G.A. and Yellen, J.L. (1990) The fair wage-effort hypothesis and unemployment. Quarterly Journal of Economics 105: 255-283.

Bardsley, N. (2008) Dictator game giving: altruism or artefact? Experimental Economics 11: 122-133.

Bewley, T.F. (1999) Why Wages Don't Fall During a Recession. Cambridge, MA: Harvard University Press.

Blumkin, T., Ruffle, B. and Ganun, Y. (2012) Are income and consumption taxes ever really equivalent? Evidence from a real-effort experiment with real goods. European Economic Review 56: 1200-1219.

Bolton, G. and Ockenfels, A. (2000) ERC: a theory of equity, reciprocity and competition. American Economic Review 90: 166-193.

Brandts, J. and Charness, G. (2004) Do labour market conditions affect gift exchange? Some experimental evidence. Economic Journal 114: 684-708.

Brandts, J., Gërxhani, K., Schram, A. and Ygosse-Battisti, J. (2010) Size doesn't matter! Gift exchange in experimental labor markets. Journal of Economic Behavior \& Organization 76: 544-548.

Brown, M., Falk, A. and Fehr, E. (2004) Relational contracts and the nature of market interactions. Econometrica 72: 747-780.

Brown, M., Falk, A. and Fehr, E. (2012) Competition and relational contracts: the role of unemployment as a disciplinary device. Journal of the European Economic Association 10: 887-907.

Charness, G. (2004) Attribution and reciprocity in an experimental labor market. Journal of Labor Economics 22: 665-688.

Charness, G. and Kuhn, P. (2007) Does pay inequality affect worker effort? Experimental evidence. Journal of Labor Economics. 25: 693-723.

Charness, G. and Kuhn, P. (2011) Lab labor: what can labor economists learn from the lab? In Handbook of Labor Economics (Vol. 4A, pp. 229-330). North Holland: Elsevier.

Charness, G., Frechette, G. and Kagel, J. (2004) How robust is laboratory gift exchange?. Experimental Economics 7: 189-205.

Chetty, R., Looney, A. and Kroft, K. (2009) Salience and taxation: theory and evidence. American Economic Review 99: 1145-1177.

Davis, D.D. and Holt, C.A. (1993) Experimental Economics. Princeton, NJ: Princeton University Press.

Duersch, P., Oechssler, J. and Vadovic, R. (2012) Sick pay provision in experimental labor markets. European Economic Review 56: 1-19.

Dufwenberg, M. and Kirchsteiger, G. (2004) A theory of sequential reciprocity. Games and Economic Behavior 47: 268-298.

Eriksson, T. and Villeval, M.C. (2012) Respect and relational contracts. Journal of Economic Behavior \& Organization 81: 286-298.

Falk, A. and Fischbacher, U. (2006) A theory of reciprocity. Games and Economic Behavior 54: 293-315.

Falk, A., Fehr, E. and Zehnder, C. (2006) Fairness perceptions and reservation wages. The behavioral effects of minimum wage laws. The Quarterly Journal of Economics 121: 1347-1381.

Fehr, E. and Falk, A. (1999) Wage rigidity in a competitive incomplete contract market. Journal of Political Economy 107: 106-134.

Fehr, E. and Gächter, S. (2002) Do incentive contracts crowd out voluntary cooperation? IEW Working Papers No. 034.

Fehr, E. and Schmidt, K.M. (1999) A theory of fairness, competition and co-operation. Quarterly Journal of Economics 114: 817-868.

Fehr, E. and Schmidt, K.M. (2007) Adding a stick to the carrot? The interaction of bonuses and fines. American Economic Review 97: 177-181.

Fehr, E. and Tyran, J.-R. (2001) Does money illusion matter? American Economic Review 91: 1239-1262. 
Fehr, E., Kirchsteiger, G. and Riedl, A. (1993) Does fairness prevent market clearing? An experimental investigation. Quarterly Journal of Economics 108: 437-460.

Fehr, E., Kirchsteiger, G. and Riedl, A. (1996) Involuntary unemployment and non-compensating wage differentials in an experimental labour market. Economic Journal 106: 106-121.

Fehr, E., Gächter, S. and Kirchsteiger, G. (1997) Reciprocity as a contract enforcement device: experimental evidence. Econometrica 65: 833-860.

Fehr, E., Kirchler, E., Weichbold, A. and Gächter, S. (1998a) When social norms overpower competition: gift exchange in experimental labor markets. Journal of Labor Economics 16: 324-351.

Fehr, E., Kirchsteiger, G. and Riedl, A. (1998b) Gift exchange and reciprocity in competitive experimental markets. European Economic Review 42: 1-34.

Fehr, E., Fischbacher, U. and Tougareva, E. (2002) Do high stakes and competition undermine fairness? Evidence from Russia. IEW Working Paper No. 120.

Fehr, E., Klein, A. and Schmidt, K. (2007) Fairness and contract design. Econometrica 75: 121-154.

Fehr, E., Goette, L. and Zehnder, C. (2009) A behavioral account of the labor market: the role of fairness concerns. Annual Review of Economics 1: 355-384.

Gächter, S. and Thöni, C. (2010) Social comparison and performance: experimental evidence on the fair wage-effort hypothesis. Journal of Economic Behavior \& Organization 76: 531-543.

Gächter, S., Nosenzo, D. and Sefton, M. (2012) The impact of social comparisons on reciprocity. Scandinavian Journal of Economics 114: 1346-1367.

Gneezy, U. and List, J.A. (2006) Putting behavioral economics to work: testing for gift exchange in labor markets using field experiments. Econometrica 74: 1365-1384.

Hannan, R., Kagel, J. and Moser, D. (2002) Partial gift exchange in an experimental labor market: impact of subject population differences, productivity differences, and effort requests on behavior. Journal of Labor Economics 20: 923-951.

Hennig-Schmidt, H., Rockenbach, B. and Sadrieh, K. (2010) In search of workers' real effort reciprocity - a field and a laboratory experiment. Journal of the European Economic Association 8: 817-837.

Huck, S., Seltzer, A. and Wallace, B. (2011) Deferred compensation in multiperiod labor contracts: an experimental test of Lazear's model American Economic Review 101: 819-843.

Irlenbusch, B. and Sliwka, D. (2005) Transparency and reciprocal behavior in employment relations. Journal of Economic Behavior \& Organization 56: 383-403.

Kagel, J.H. and Owens, M.F. (2010) Minimum wage restrictions and employee effort in incomplete labor markets: an experimental investigation. Journal of Economic Behavior \& Organization 73: 317-326.

Kahneman, D. and Tversky, A. (1979) Prospect theory: an analysis of decision under risk. Econometrica 47: 263-292.

Kerschbamer, R. and Kirchsteiger, G. (2000) Theoretically robust but empirically invalid? An experimental investigation into tax equivalence. Economic Theory 16: 719-734.

Kube, S., Maréchal, M.A. and Puppe, C. (2012) The currency of reciprocity - gift-exchange in the workplace. American Economic Review 102: 1644-1662.

Kube, S., Maréchal, M.A. and Puppe, C. (forthcoming). Do wage cuts damage work morale? Evidence from a natural field experiment. Journal of the European Economic Association.

Lazear, E. (1979) Why is There Mandatory Retirement? Journal of Political Economy 87: 1261-1284.

Lei, V. and Noussair, C.N. (2007) Equilibrium selection in an experimental macroeconomy. Southern Economic Journal 74(2): 448-482.

Levine, D.K. (1998) Modeling altruism and spitefulness in experiments. Review of Economic Dynamics 1: 593-622.

List, J.A. (2007) On the interpretation of giving in dictator games. Journal of Political Economy 115: 482-493.

Maximiano, S., Sloof, R. and Sonnemans, J. (2007) Gift exchange in a multi-worker firm. Economic Journal 117: $1025-1050$.

Maximiano, S., Sloof, R. and Sonnemans, J. (2013) Gift exchange and the separation of ownership and control. Games and Economic Behavior 77: 41-60.

Nosenzo, D. (forthcoming). Pay secrecy and effort provision Economic Inquiry.

Noussair, C.N., Plott, C. and Riezman, R. (1995) An experimental investigation of the patterns of international trade. American Economic Review 85: 462-491. 
Noussair, C.N., Plott, C. and Riezman, R. (2007) Production, trade and exchange rates in large experimental economies. European Economic Review 51: 46-76.

Ortona, G., Ottone, S., Ponzano, F. and Scacciati, F. (2008) Labour supply in presence of taxation financing public services. An experimental approach. Journal of Economic Psychology 29: 619-631.

Pereira, P., Silva, N. and Silva, J. (2006) Positive and negative reciprocity in the labor market. Journal of Economic Behavior \& Organization 59: 406-422.

Rabin, M. (1993) Incorporating fairness into game theory and economics. American Economic Review 83: $1281-1302$.

Riedl, A. and Tyran, J. (2005) Tax liability side equivalence in gift-exchange labor markets. Journal of Public Economics 89: 2369-2382.

Riedl, A. and Van Winden, F. (2001) Does the wage tax system cause budget deficits? A macro-economic experiment. Public Choice 109: 371-394.

Riedl, A. and Van Winden, F. (2007) An experimental investigation of wage taxation and unemployment in closed and open economies. European Economic Review 51: 871-900.

Riedl, A. and Van Winden, F. (2012) Input versus output taxation in an experimental international economy European Economic Review 56: 216-232.

Shapiro, C. and Stiglitz, J.E. (1984) Equilibrium unemployment as a worker discipline device. American Economic Review 74: 433-444.

Siang, C.K., Requate, T. and Waichman, I. (2011) On the role of social wage comparisons in gift-exchange experiments. Economics Letters 112: 75-78. 